\title{
Automatic Blood Pressure Detector Using Arduino to Measure Blood Pressure in Indonesian People Age 19-27 Years Old
}

\author{
Ratnadewi $^{1 *}$, Mohammad Faizal Ramdhani ${ }^{2}$, Nuning Kurniasih ${ }^{3}$, Lusi Dwi Putri ${ }^{4}$, Parwito ${ }^{5}$, Dahlan Abdullah ${ }^{6}$, \\ Tri Listyorini ${ }^{7}$, Muhammad Ilham Bakhtiar ${ }^{8}$, Ricardo Freedom Nanuru', Robbi Rahim ${ }^{10}$ \\ ${ }^{1}$ Department of Electrical Engineering, Universitas Kristen Maranatha,Bandung, Indonesia \\ ${ }^{2}$ Department of Electrical Engineering, Universitas Kristen Maranatha,Bandung, Indonesia \\ ${ }^{3}$ Faculty of Communication Sciences, Library and Information Science Program, Universitas Padjadjaran, Bandung, Indonesia \\ ${ }^{4}$ Universitas Lancang Kuning, Indonesia \\ ${ }^{5}$ Department of Agrotechnology, Universitas Ratu Samban, Indonesia \\ ${ }^{6}$ Department of Informatics, Universitas Malikussaleh, Aceh, Indonesia \\ ${ }^{7}$ Department of Informatics Engineering, Universitas Muria Kudus, Indonesia \\ ${ }^{8}$ Universitas Negeri Makassar, Indonesia \\ ${ }^{9}$ Universitas Halmahera, Indonesia \\ ${ }^{10}$ School of Computer and Communication Engineering, Universiti Malaysia Perlis, Kubang Gajah, Malaysia \\ *Corresponding author E-mail:ratnadewi.bandung@gmail.com
}

\begin{abstract}
No doubt every person wants to be healthy in order to move well. One of the health conditions to note is to keep blood pressure. many people sick one cause is high blood pressure. there are two methods of measuring blood pressure ie invasive and non-invasive. using the oscillometric method the measurement can be performed automatically, with the help of a piezoresistive pressure sensor connected to arduino mega 2560. so that the measurement data in the form of name, age, and blood pressure can be stored on the SD card that can be read again if needed. In this research the difference between the systolic or diastolic values of blood pressure reading with analog devices compared with automatic blood pressure reading tool and obtained that the average difference of $3,265 \mathrm{mmHg}$ for systolic value and $6,165 \mathrm{mmHg}$ for diastolic. Then this difference is used in the calibration process so that the result of automatic blood pressure reading tool is better. The result of calibration reading tool has $99.47 \%-99.82 \%$ accuracy
\end{abstract}

Keywords: Arduino, Blood pressure, Oscillometric, Pressure Sensor.

\section{Introduction}

High blood pressure is one cause of death or severe illness[1] Hypertension is a silent killer disease or so-called "the silent killer" because the original cause is unknown or without symptoms at all. Hypertension can cause various complications that can lead to several other diseases, such as heart disease, blindness, kidney and stroke until death. According to RISKESDAS (Basic Health Research) in 2010 hypertension can attack anyone, various age groups also socioeconomic status. Hypertension disease in Indonesian population aged 18 years and over is $31.7 \%$ of the total population in Indonesia. People suffering from hypertension should take regular blood pressure measurements, because blood pressure is a vital sign of humans that can change over time. Measuring blood pressure can be used as a benchmark for patients in seeking medical help to assist their condition. There are some microcontroller can be used in system that is [2]ATMega, [3]Arduino, ARM, etc. In this research we are used Arduino. Measuring blood pressure can be done anywhere. By having a blood pressure meter itself, hypertension patients can measure their blood pressure and know when to meet health workers. In this Research the author tries to design and make digital blood pressure monitoring system that can be used easily and efficiently.
[4]The automatic blood pressure monitor system equipped using ARM and DSP have been promoted. [5] This paper is used GSM to transfer data from Automatic blood pressure to SD card to save the data measurement. In this paper the automatic blood pressure monitor system equipped with data storage using arduino mega 2560.

\section{Method}

The block diagram automatic blood pressure monitor system equipped with data storage using arduino mega 2560 can be described in Fig. 1.

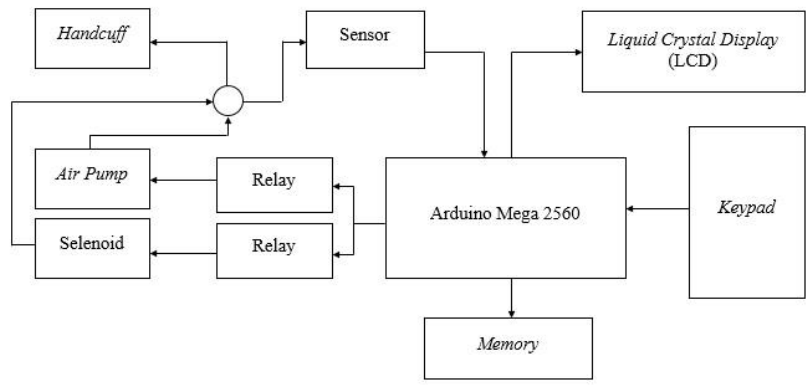

Fig. 1: The System Block Diagram 
The working system of this blood pressure tool consists of hardware systems and software systems[6][7]. The hardware system of this tool consists of Arduino and Keypad that serves as a controller[8] work from a blood pressure device. The sensor serves as a detector of blood pressure, Liquid Crystal Display (LCD) 4 lines as the name, age and diastolic systolic display, and air pump and Solenoid as the pump and air regulator that will enter the handcuff and SD Card Module Arduino for storage data of the results of measurements. While the software system tool is a program created using Arduino Software (IDE) with Language $\mathrm{C}$ arduino. Block diagram work system automatic blood pressure monitor tool that can store data measurements using Arduino work tool is almost the same as analog blood pressure, namely by pairing the cuff on the part of the brachial artery located on the elbow crease. Furthermore, the work of this tool begins with activating the power supply. After the power supply is active then the whole tool will be active. The tool will prompt the user to enter his or her data in the name and age, enter the data through the keypad, then press OK on the available keypad, the automatic blood pressure tool will start working. Arduino will give an order on Air pump that will pump air slowly into the cuff, while the sensor that detects the air pressure inside the cuff will continuously monitor the pressure until the desired pressure is reached $(170 \mathrm{mmHg})$. When the required pressure is reached, the blood flow will stop for a while because the cuff presses strongly on the blood vessels. Next the valve will automatically open and the pressure on the cuff will slowly drop. As the pressure drops, the cuff strength presses on the blood vessels as well. When the pulse occurs for the first time, the pressure on the cuff will change slightly, and the pressure changes will be detected by the sensor[9], which will then be processed by the Arduino as systolic pressure. As the air pressure drops on the cuff, the pulse detected by the sensor will gradually disappear and that is when the diastolic pressure values are obtained. Arduino serves as the "brain" of the system work tool, namely as a data processing center in the form of analog voltage signal that will be converted into digital data with ADC, where there is already an internal ADC and also as a processor to display text and numbers on the LCD. After completion of the data in the form of name, age and blood pressure results, the data will be directly stored on the Memory SD Card and can be reviewed again the results by means of SD Card connected to the computer.

The initial process of making electronics circuit is the making of arduino blood pressure circuit scheme to be made. This design uses the professional proteus 8 software, the schematic looks Arduino Mega 2560 as a central control system Blood Pressure Monitor. All components of Keypad, LCD, I2C, SD Card Module, Relay Module, Valve, Air Pump and MPX 5700 AP connected with Arduino.

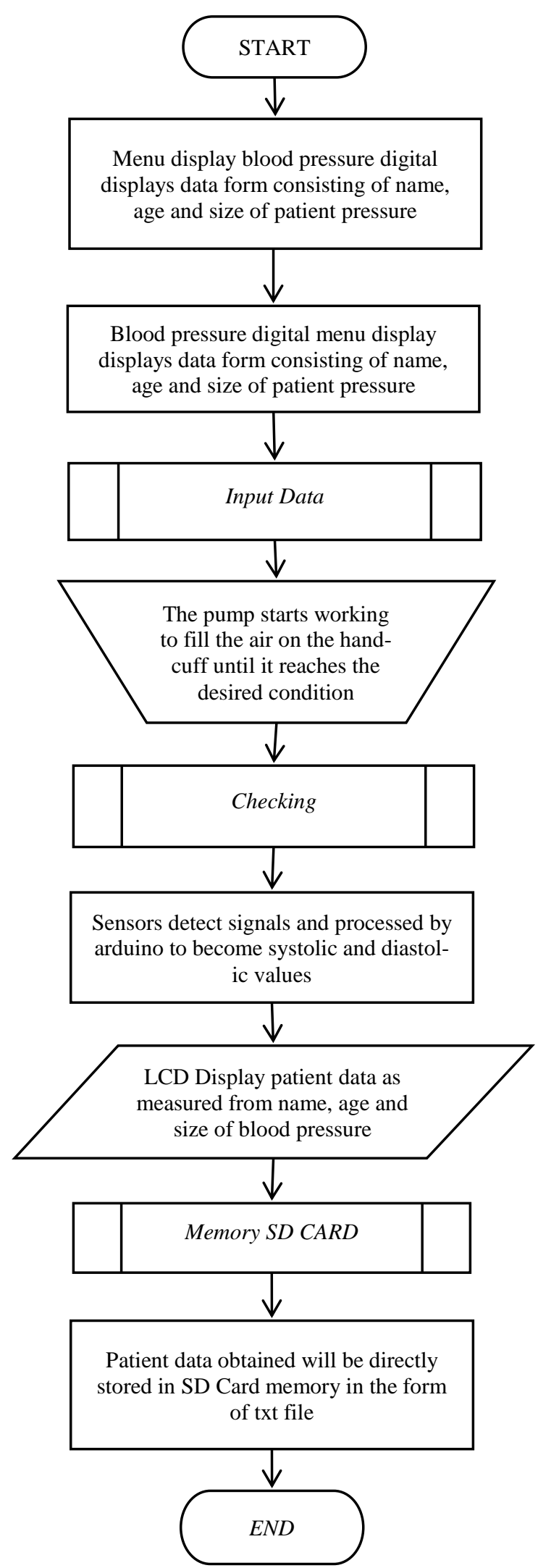

Fig. 2: Flowchart blood pressure detector

\section{Result and Discussion}

In testing the basic circuit of this pressure sensor uses a basic circuit of pressure sensors connected with blood pressure, multimeter, and automatic pump. In this test the blood pressure is connected directly to the MP5700AP pressure sensor and an automatic pump with a T-shaped connection system. Then the multimeter is con- 
nected to a pressure sensor and set to measure the voltage. The basic circuit of pressure sensor tested by using blood pressure can be seen in Fig. 3.

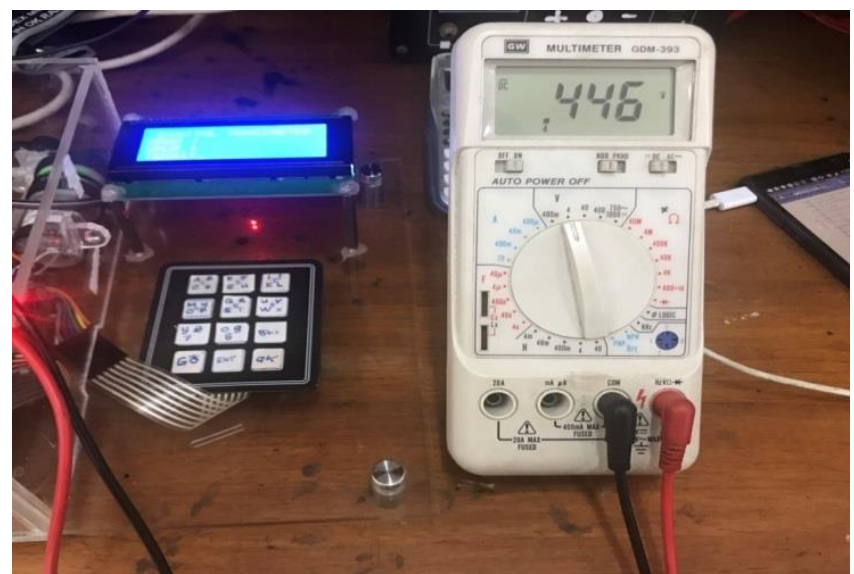

Fig. 4: Pressure sensor base network testing.

From Fig. 3, the multimeter is set to measure the voltage generated when applied pressure through the manual pump. Then the voltage results are recorded to determine the effect of the applied pressure on the resulting voltage changes. As for result of test of base circuit of MPX5700AP pressure sensor can be formed graph relation between pressure $\mathrm{x}(\mathrm{mmHg})$ and voltage $(\mathrm{mV})$ on y axis as shown in Fig. 4.

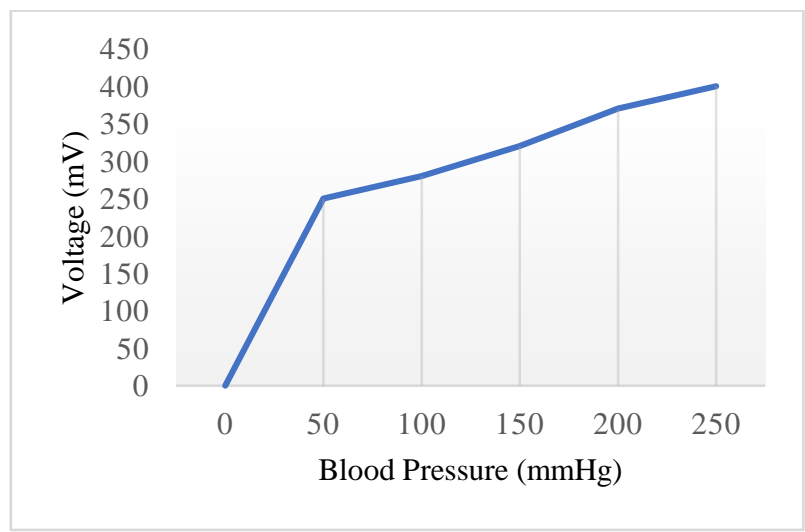

Fig.4: Changes in voltage $(\mathrm{mV})$ to pressure $(\mathrm{mmHg})$

Fig. 4 shows the relationship between pressure (mmHg) coming from the automatic pump and the voltage as the output of this pressure sensor is proportional and linear. This means the greater the pressure the greater the voltage generated.

The sensor output is still a voltage then it must still be converted into $\mathrm{kPa}$ pressure unit. The formula to convert to $\mathrm{kPa}$ must match what is already available on the datasheet. Here's how to change the output voltage to $\mathrm{kPa}$ with MPX $5700 \mathrm{AP}$ sensor characteristic equation.

Given the sensor output voltage is $414,085 \mathrm{mV}$ will be converted to $\mathrm{kPa}$ value. By using the sensor characteristic equation

$V_{\text {out }}=V_{S} \times(0.0012858 \times k P a+0.04)$

Assume $V_{S}=5.0 \mathrm{~V}$ and $V_{\text {out }}=414,1 \mathrm{mV}$ then $k P a=33.3$. Because the required is $\mathrm{mmHg}$ then the $\mathrm{kPa}$ value can be changed to $\mathrm{mmHg}$ with the following equation

$\mathrm{mmHg}=\mathrm{kPa} \times 7,500617$

The result $33.3=249.7663994 \mathrm{mmHg}$.

The steps taken in the measurement of the DC motor circuit and solenoid are as follows: first connect the circuit to $+5 \mathrm{~V}$ power supply. Second connect network with arduino mega 2560 to measure voltage on DC and solenoid motors.

Third record the measurement results (Table.1).

Table 1: Measurement result of solenoid motors

\begin{tabular}{|c|c|c|}
\hline $\begin{array}{c}\text { Voltage } \\
\text { (Volt) }\end{array}$ & Motor DC & Solenoid \\
\hline VIN & 6 Volt & 5,4 Volt \\
\hline
\end{tabular}

This test aims to know that the Liquid Crystal Display Test (LCD) $16 \times 4$. is in good condition to display any characters either columns or rows sent through arduino. The test is done by sending the basic program for the LCD into the arduino and displays it on the 16x4 LCD (Fig. 5). Test results are as follows.From this test LCD displays each character clearly according to input given from arduino, so it can be concluded LCD in good condition no damage.

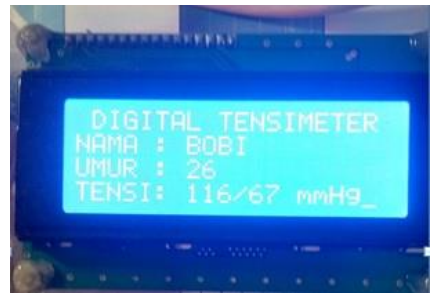

Fig.5:16x4 LCD Testing

This test aims to know that entering a character to create a name and enter a number for the age from the keypad to the LCD according to the name and age of the patient to be checked for blood pressure.From this test results LCD display the name and age vary, according to patient data to be measured, so it can be concluded inputting name and age can run well and can enter the name of age that we will input from keypad to LCD. In Fig. 6 memory SD Card test aims to find out that the blood pressure measurements data whose name, age and measurable blood pressure measurements will be stored directly on the Memory SD Card and can be re-evaluated by the SD card on the computer.

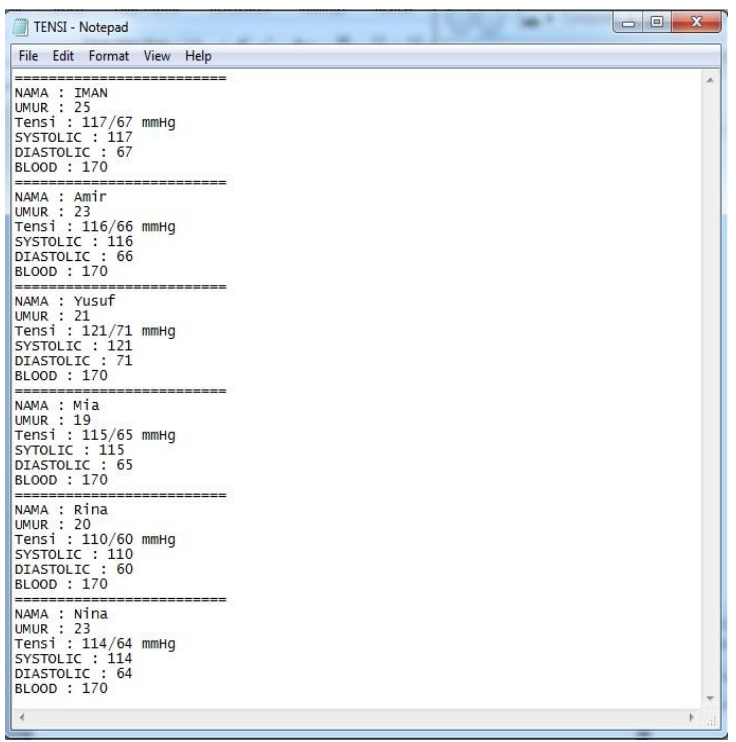

Fig.6: Data of measurement results stored on SD Card

Blood pressure measurements were performed before and after the calibrated blood pressure measurements to obtain the systolic and diastolic values of the device designed to be not much different from the analog blood pressure tool, the test results were divided into two groups of male and female, first before calibration and the second after calibration with a 5 minute interval. Fig. 7 show systolic blood pressure of male, Fig. 8 show systolic blood pressure of female, Fig. 9 show diastolic blood pressure of male, Fig. 10 show diastolic blood pressure of female. From this diagram we 
looked that after calibration the measurement have achievement much better than before calibration.

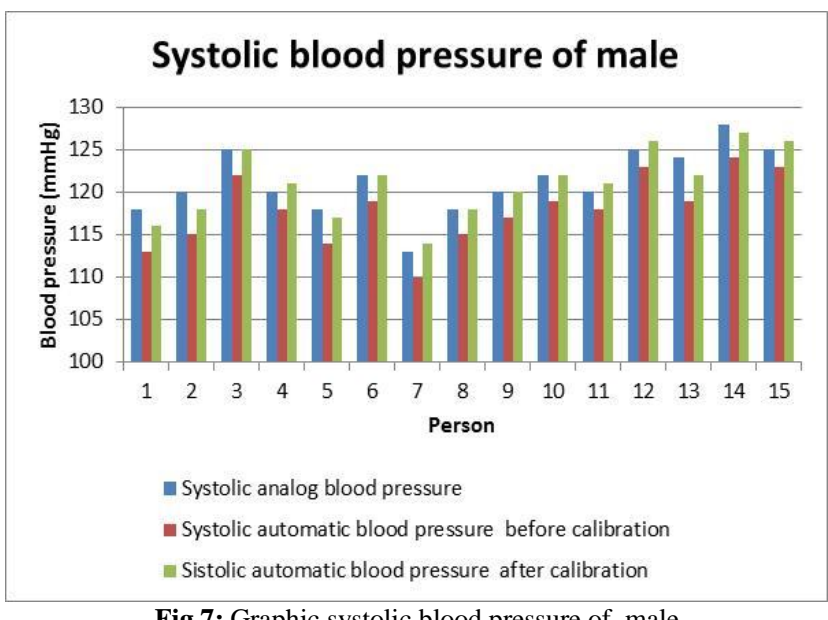

Fig.7: Graphic systolic blood pressure of male

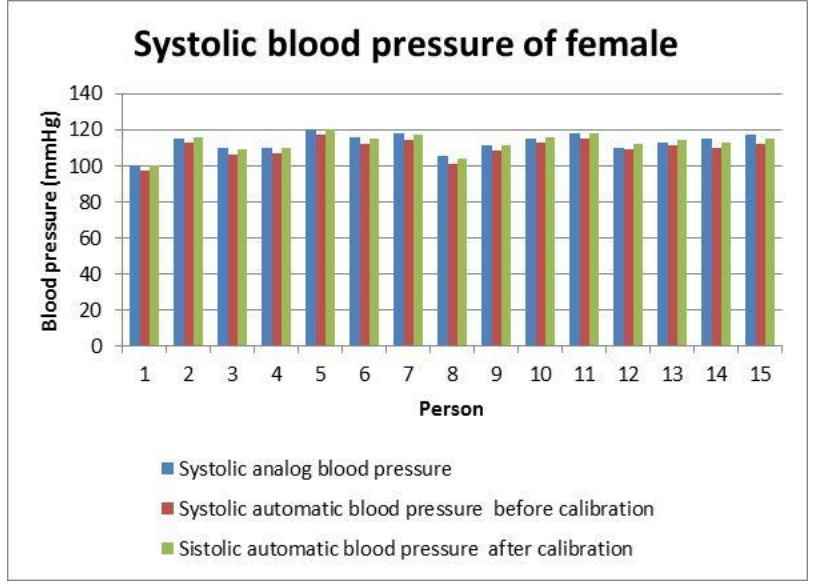

Fig.8: Graphicsystolic blood pressure of female

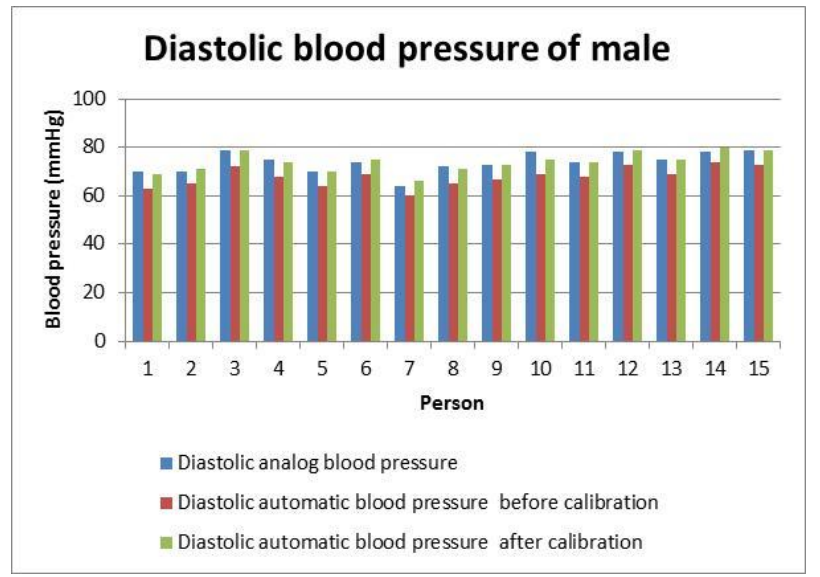

Fig. 9: Graphicdiastolic blood pressure of male

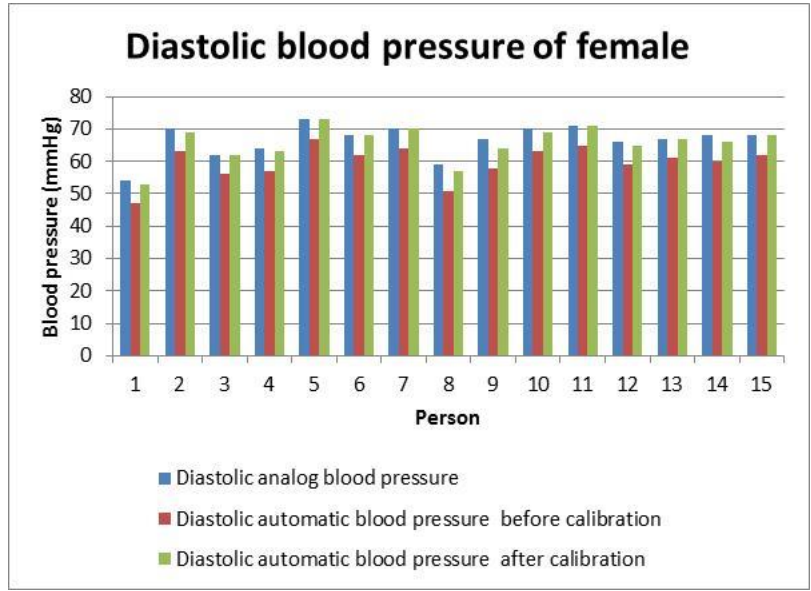

Fig. 10:Graphicdiastolic blood pressure of female

\section{Conclusion}

It has been successfully designed and realized automatic blood pressure tool using arduino mega 2560 based oscillometric method which can save the results of datameasurement and has successfully designed the system to enter the data name, age and blood pressure into the SD card memory in the automatic blood pressure tool.

\section{References}

[1] Hypertension Canada, "Hypertension Canada 2017 Guidelines for management of Hypertension," Hypertens. Canada, 2017.

[2] I. B. A. I. Iswara and I. G. M. N. Desnanjaya, "Trainer ATMEGA32 Sebagai Media Pelatihan Mikrokontroler dan Arduino," Resistor, vol. 1, no. 1, pp. 55-64, 2018.

[3] M. Margolis, Arduino Cookbook, First Edit. O'Reilly, 2011.

[4] L. Khuon, T. Camise, C. Banan, and K. Buckley, "Contrasting Blood Pressure Measurement Approaches in a Freshman Engineering Design Project Lunal Khuon, Timothy Camise Clayton Bannan and Kevin Buckley Department of Electrical and Computer Engineering," in Spring 2012 Mid-Atlantic ASEE Conference, 2012.

[5] M. K. Chaithanya, K. V. K. Kishore, and A. Srinivasulu, "Continues Blood Pressure Measurement and Data Logging Device with SMS Alert," Int. J. Multimed. Ubiquitous Eng., vol. 9, no. 8, pp. 25-40, 2014.

[6] A. Prijono, A. D. Hangkawidjaja, Ratnadewi, and A. S. Ahmar, "Verification Image of the Veins on the Back Palm with Modified Local Line Binary Pattern (MLLBP) and Histogram," J. Phys. Conf. Ser., vol. 954, no. 1, 2018.

[7] A. Rubin, High Blood PRESSURE, Second Edi. Wiley Publishing, Inc., 1973.

[8] T. Listyorini and R. Rahim, "A prototype fire detection implemented using the Internet of Things and fuzzy logic," World Trans. Eng. Technol. Educ., vol. 16, no. 1, pp. 42-46, 2018.

[9] J. Fraden, Handbook of Modern Sensors, Third Edit. Newyork: Springer, 2004 